\title{
Effect of Heating Prior to Gemcitabine Exposure on Therapeutic Outcomes in Combination Therapies
}

\author{
SATOKO ADACHI, SATOSHI KOKURA*, TOSHIKAZU YOSHIKAWA \\ Department of Molecular Gastroenterology and Hepatology, Kyoto Prefectural University of Medicine, \\ Kawaramachi-hirokoji, Kamigyo-ku, Kyoto 602-8566, Japan
}

\begin{abstract}
Using chemotherapy alone, it is difficult to cure patients with solid tumors. However, chemotherapy combined with heat treatment enhances cytotoxicity by improving drug delivery to tumor tissues, leading to improvements in the cure rate.

Nuclear factor-kappa B $(\mathrm{NF}-\varkappa \mathrm{B})$ has been reported to be activated by chemotherapy in some cancer cell lines, and $\mathrm{NF}-\varkappa \mathrm{B}$ activation is one mechanism through which tumors can become resistant to chemotherapy. Heat treatment-induced heat shock protein 70 (Hsp70) was reported to inhibit I kappa $\mathrm{B}(\mathrm{I} \varkappa-\mathrm{B})$ kinase $(\mathrm{IKK})$, resulting in the inhibition of $\mathrm{NF}-\varkappa \mathrm{B}$ activation. In view of this observation, it appeared to be possible that activation of $\mathrm{NF}-\varkappa \mathrm{B}$ in a pancreatic cell line might be inhibited by heat treatment, leading to an enhancement of gemcitabine-induced cytotoxicity. However, the timing of the heat treatment is also very important in producing chemosensitization when combined with chemotherapy.
\end{abstract}

In this review, the timing of a heat treatment in relation to a gemcitabine treatments is discussed, along with the mechanisms leading to sensitization in combination therapy.

Key Words: heat treatment, gemcitabine, human pancreatic cancer, apoptosis, $\mathrm{NF}-\varkappa \mathrm{B}$

\section{Introduction}

Although a heat treatment can produce a temperature-dependent cytotoxicity to help cure cancer, its therapeutic efficacy is limited. Recently, chemotherapy has made impressive progress, and the outcomes of therapy for inoperable cancer and recurrent cancer have improved dramatically due to the development of new anti-cancer agents such as docetaxel, paclitaxel, irinotecan, oxaliplatin, and gemcitabine. There is evidence that the anti-cancer effects of these newly developed drugs can be enhanced by a heat treatment in in vivo and in vitro studies (Table I). However, successful clinical response rates to chemotherapy are no more than $50 \%$, and this rate is usually approximately $20-30 \%$ currently. Furthermore a major problem is that the effect of chemotherapy is impaired by the development of resistance to drugs over several treatment cycles, and it is difficult to treat patients and minimize therapeutic side-effects. In the clinic, one of the major purposes of heat treatment is to enhance chemotherapeutic and radiation

Received 10 August, 2010, Accepted 2 September, 2010. ${ }^{*}$ Corresponding author; Tel, +81-75-251-5508; Fax, +81-75-251-0710 ; e-mail, s-kokura@koto.kpu-m.ac.jp

doi : $10.3191 /$ thermalmed. 26.75

(C) 2010 Japanese Society for Thermal Medicine 
Thermal Med, 26 [3] : 75-85, 2010.

therapeutic sensitivity. However, it is possible to overcome these problems by using chemotherapy combined with heat treatments.

In this review, the effects of chemotherapy are discussed, and in particular, the effects of gemcitabine $(30 \mu \mathrm{M})$ on human pancreatic cancer cell lines when combined with a heat treatment $\left(43^{\circ} \mathrm{C}, 1 \mathrm{~h}\right)$. The effect of the timing of the heat treatment in relation to the timing of chemotherapy is also considered.

Table I. Heat sensitization in combination with chemotherapy

\begin{tabular}{|c|c|c|c|c|}
\hline Author & Year & Exp. type & Timing of chemotherapy & Ref. \\
\hline \multicolumn{5}{|l|}{ Docetaxel } \\
\hline Rietbroek RC & 1997 & in vitro & just before hypertermia & $(12)$ \\
\hline Dumontet $\mathrm{C}$ & 1998 & in vitro & & $(13)$ \\
\hline Mohamed F & 2003 & in vitro & just before hypertermia & $(14)$ \\
\hline Mohamed F & 2004 & in vivo & before hypertermia & $(15)$ \\
\hline \multicolumn{5}{|l|}{ Paclitaxel } \\
\hline Cividalli A & 2000 & in vitro & different times in relation to hyperthermia & $(17)$ \\
\hline Othman T & 2001 & in vitro & $1 \mathrm{~h}$ before hyperthermia & $(18)$ \\
\hline Mohamed F & 2003 & in vitro & & $(14)$ \\
\hline Michalakis $\mathbf{J}$ & 2005 & in vitro & simultaneous & (19) \\
\hline \multicolumn{5}{|l|}{ Irinotecan } \\
\hline Katschinski DM & 1999 & in vitro & simultaneous & $(22)$ \\
\hline Mohamed F & 2003 & in vitro & & (14) \\
\hline Le Page $\mathrm{S}$ & 2006 & in vitro & & (23) \\
\hline Makizumi R & 2008 & in vitro & $24 \mathrm{~h}$ after hyperthermia & $(24)$ \\
\hline \multicolumn{5}{|l|}{ Oxaliplatin } \\
\hline Rietbroek RC & 1997 & in vitro & $1 \mathrm{~h}$ after hyperthermia & $(25)$ \\
\hline Urano $\mathrm{M}$ & 2002 & in vitro & & $(26)$ \\
\hline Mohamed F & 2003 & in vitro & & $(14)$ \\
\hline Atallah D & 2004 & in vitro & & $(27)$ \\
\hline Makizumi R & 2008 & in vitro & $24 \mathrm{~h}$ after hyperthermia & $(28)$ \\
\hline \multicolumn{5}{|l|}{ Gemcitabine } \\
\hline Haveman $\mathbf{J}$ & 1995 & in vitro & simultaneous & (34) \\
\hline Van Bree C & 1999 & in vitro & $48 \mathrm{~h}$ before hyperthermia & $(35)$ \\
\hline Mohamed F & 2003 & in vitro & & $(14)$ \\
\hline Vertrees RA & 2005 & in vitro & $24 \mathrm{~h}$ after hyperthermia & $(36)$ \\
\hline
\end{tabular}

\section{The advantage of a heat treatment plus chemotherapy}

An extensive review of efforts to combine heat treatment with chemotherapy was published in $1995^{1)}$. Thermal enhancement of drug cytotoxicity was accompanied by cell death without increasing oncogenic potentials. The induction of genetically defined stress responses can deliver signals to activate the host's immune system. The positive results of randomized trials clearly established that heat treatment in combination with chemotherapy is a novel clinical modality for the treatment of cancer ${ }^{2-4)}$. Heat treatment targets the action of chemotherapy within heated tumor regions without affecting systemic 
toxicity ${ }^{5}$.

Improved drug delivery relies on the fact that local heating results in the perforation of tumor blood vessels, microconvection in the interstitium, and in the perforation of cancer cell membranes. In summary, heat treatment enhances drug delivery from the blood into cancer cells with minimal thermal and mechanical damage to normal tissues. In addition, heat treatment can render tumor cells temporarily more sensitive to the damaging effects of radiation or chemotherapeutics ${ }^{6}$. Furthermore it has been shown that mitomycin $\mathrm{C}$, nitrosoureas, cisplatin, doxorubicin and mitoxantrone, in addition to heat treatment and chemotherapy, can counteract drug resistance ${ }^{7}$. It was also found that some newly developed drugs such as docetaxel, paclitaxel, irinotecan, oxaliplatin and gemcitabine lead to thermal sensitization.

It was concluded that the mechanism responsible for thermal sensitization was the enhancement of damage to cellular membranes, proteins and DNA, improvements in the rate of drug uptake into the cells ${ }^{8,9)}$, and the inhibition of DNA repair ${ }^{10,11)}$.

Antitubulin agents such as docetaxel are especially interesting agents to consider for use in combination with therapeutic heat treatments: this is because their intracellular target, the soluble tubulin/microtubule complex, is a highly temperature dependent structure, at least in vitro ${ }^{12-15}$. The rationale for the use of a heat treatment with docetaxel is based on two factors : a mild heat treatment causes disorganization in the microtubule system, and docetaxel is considered to be a microtubule stabilizing agent ${ }^{16)}$. Furthermore, Mohamed et al. ${ }^{15)}$ suggested that heat treatment must be applied soon after this drug is administered.

The antineoplastic agent paclitaxel (PTX) is known to arrest cell cycle progression and induce apoptosis. Therapy consisting of PTX in combination with heat treatment may be useful ${ }^{14,17-19)}$. Othman et al. ${ }^{15)}$ reported that exposure of a mouse mammary cancer cell line to PTX alone caused an increase in the number of cells in the $\mathrm{G}_{2} / \mathrm{M}$ phase, while PTX applied concurrently with a $43^{\circ} \mathrm{C}$ heat treatment caused an increase in the number of cells in the $\mathrm{G}_{2} / \mathrm{M}$ and $\mathrm{S}$ phases, and both treatments resulted in a decrease in the number of cells in the $G_{0} / G_{1}$ phase of the cell cycle. On the basis of these results it can be concluded that the mechanism of PTX action at the cellular level is associated with disturbances in the cell division process. This may be attributed to the effect of PTX on the microtubule system which is a target for anti-cancer drugs ${ }^{20,21}$.

An effect of heat treatment on the active metabolite of irrinotecan, $\mathrm{SN} 38$, whas been reported ${ }^{14,22-24)}$. Katschinki et al. ${ }^{22)}$ suggested that there is a temperature-specific (i.e. $41.8^{\circ} \mathrm{C}$ ) effect on $\mathrm{SN}-38$ induced Topoisomerase (Topo) I DNA cross-linking, and that cytotoxicity resulted from temperature-dependent changes in Topo I catalytic activity. An active Topo I enzyme function is a key requirement for Topo I DNA cross-linking.

Platinum-DNA adduct formation caused by oxaliplatin is also enhanced by heat treatment ${ }^{14,25-28)}$. Rietbroek et al. ${ }^{25)}$ confirmed that heat treatments combined with platinum drugs such as cisplatin and oxaliplatin not only increased cytotoxicity, but also led to an increase in platinum-DNA adduct formation. Whether this is the mechanism responsible for the observed thermal enhancement of cytotoxicity cannot currently be answered : other mechanisms, such as an inhibition of DNA repair, might be involved ${ }^{29}$. 
In the clinic, the timing of drug administration and heat treatment is usually simultaneous, but with gemcitabine, it was reported that a heat treatment enhanced the cytotoxicity of gemcitabine, especially when the heat treatment was performed $24 \mathrm{~h}$ before exposure to gemcitabine (Fig. 1). When AsPC-1 cells were untreated, the apoptotic cell death rate was $1.5 \%$. However, $30 \mu \mathrm{M}$ gemcitabine increased the apoptotic cell death rate to $3.1 \%$. Moreover, the apoptotic cell death rate increased to $4.8 \%$ when a heat treatment was delivered before exposure to gemcitabine. In the case of MIAPaCa-2 cells, a heat treatment delivered $24 \mathrm{~h}$ before an exposure to gemcitabine also enhanced apoptosis (data not shown).

Gemcitabine, a chemotherapeutic agent with proven efficacy in the treatment of lung cancer and pancreatic cancer, is a deoxycytidine nucleoside analogue that affects several enzymes involved in DNA synthesis and repair. Once transported into the cell, Gemcitabine (dFdCyd) must be phosphorylated in order to become activated. The triphosphate form, dFdCTP, can directly inhibit DNA synthesis or inhibit replication through the addition of dFdCMP into the new DNA strand. The diphosphate form, $\mathrm{dFdCDP}$, inhibits the formation of deoxynucleoside triphosphates needed for DNA synthesis by blocking the activity of ribonucleotide reductase ${ }^{30,31)}$. Gemcitabine has been shown to cause cell cycle arrest in S-phase leading to apoptosis ${ }^{32)}$, or to be incorporated in RNA thereby inducing apoptosis due to poisoning of topoisomerase I in lung cancer cells ${ }^{33)}$.

Several investigators compared the effect of gemcitabine and heat treatment administered either simultaneously or sequentially ${ }^{14,34-36)}$. Studies have confirmed confirmed the results of Haveman
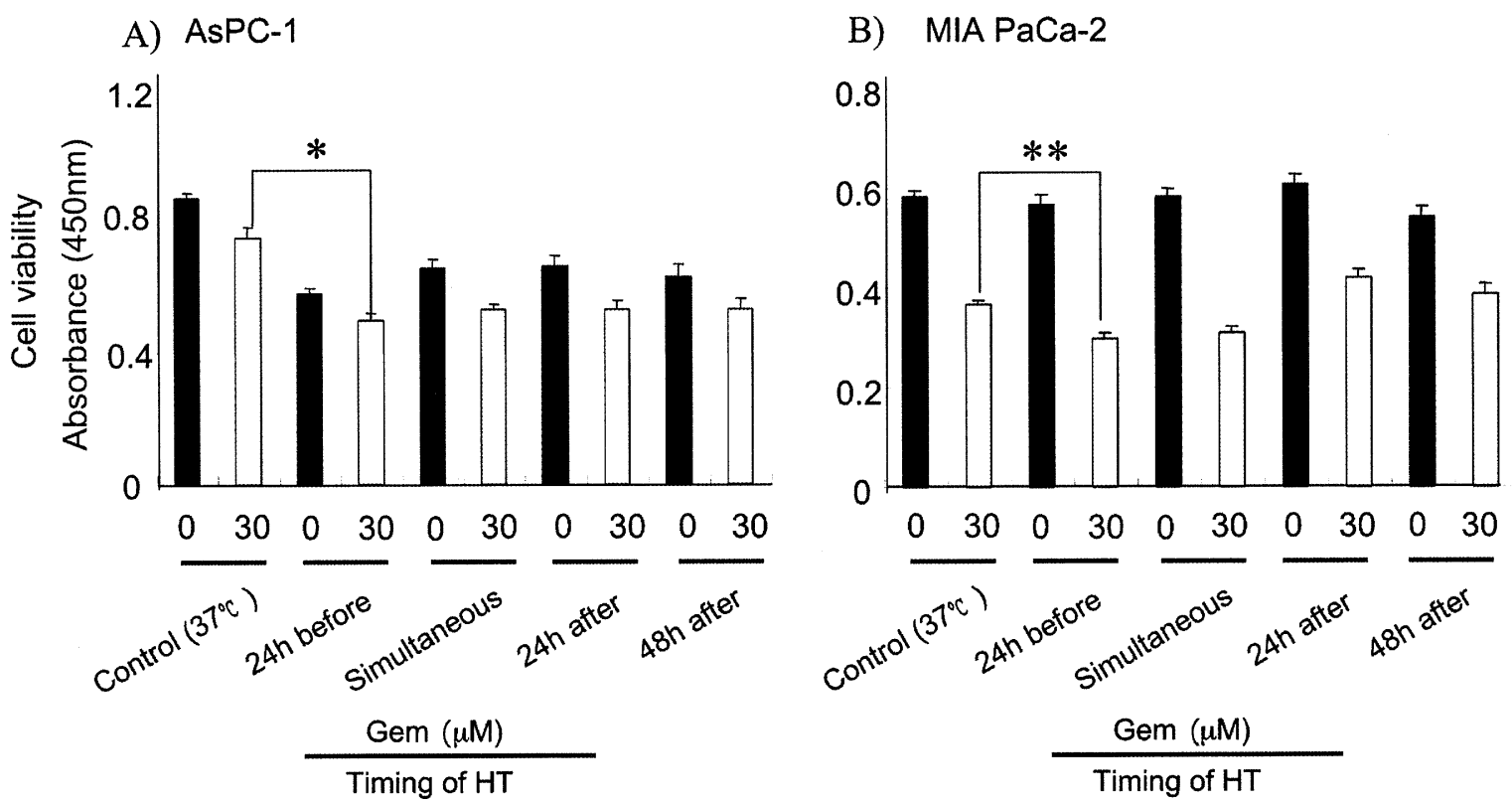

Fig. 1. Heat treatment (HT) enhanced the cytotoxicity of gemcitabine (Gem). Human pancreatic cancer cell lines AsPC-1 and MIAPaCa-2 received a heat treatment $\left(43^{\circ} \mathrm{C}, 1 \mathrm{~h}\right)$ in combination with a gemcitabine treatment $(30 \mu \mathrm{M})$ at various relative times. The solid bars represent controls (no gemcitabine), and the open bars represent $30 \mu \mathrm{M}$ gemcitabine. The time when heat was delivered relative to gemcitabine is indicated at the bottom of the figures. Cell viability was measured by the WST-8 assay. Values represent mean \pm SEM of four samples of a representative experiment; similar results were obtained in three independent experiments. ${ }^{*} P<0.01$, compared with the control in AsPC-1 cells (A). ${ }^{* * P}<0.005$, compared with the control in MIAPaCa-2 cells (B). 
et $a l .{ }^{34)}$, Van Bree et $a l .{ }^{35)}$ and Vertrees et $a l .^{36)}$ : when gemcitabine and heat treatment were administered simultaneously, there was a reduced cytotoxicity. Based on these studies and the fact that heat could inhibit the cytotoxic effects of $\mathrm{dFdC}$-metabolites, the effect of different temporal delivery patterns of $\mathrm{dFdC}$ and heat treatments on malignant human pancreatic cell lines were studied.

\section{Nuclear factor-kappa $B(N F-\varkappa B)$ and a heat treatment delivered prior to gemcitabine}

When human pancreatic cancer cell lines were exposed to gemcitabine $(30 \mu \mathrm{M})$, gemcitabine increased $\mathrm{NF}-\varkappa \mathrm{B}$ binding activity in these cells and this effect was reduced by a heat treatment (Fig. 2).

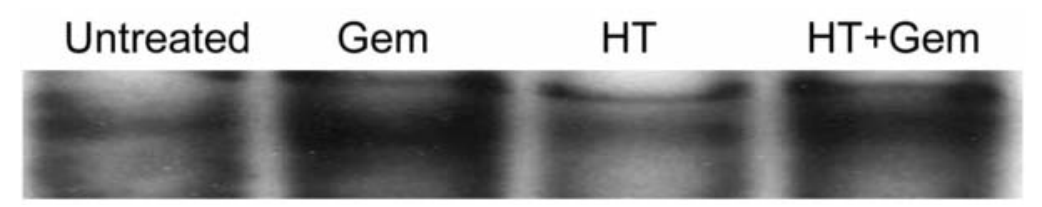

Fig. 2. Effects of gemcitabine on $\mathrm{NF}-\varkappa \mathrm{B}$ activity. Gemcitabine-induced $\mathrm{NF}-\varkappa \mathrm{B}$ levels were decreased after a combination therapy with heat treatment. The binding activity of $\mathrm{NF}-\varkappa \mathrm{B}$ was assessed after a $12 \mathrm{~h}$ gemcitabine treatment or $24 \mathrm{~h}$ after a heat treatment. AsPC-1 cells were exposed to four kinds of stimuli. The results for no treatment (control), treatment with gemcitabine alone (30 $\mu \mathrm{M})$, treatment with heat alone $\left(43^{\circ} \mathrm{C}, 1 \mathrm{~h}\right)$, and heat treatment combined with gemcitabine treatment are shown.

The level of proteins which are associated with $\mathrm{NF}-\varkappa \mathrm{B}$ was examined with western blotting in AsPC-1 and MIAPaCa-2 cells. Increasing levels of Hsp70 were induced by heat treatment, and this effect was further increased by a combination of gemcitabine and heat treatment in MIAPaCa-2 cells. In contrast, gemcitabine alone did not affect the protein levels of Hsp70. In AsPC-1 cells, increased levels of Hsp70 protein were also induced by heat treatment (data not shown). However, western blotting showed that the combination of gemcitabine and heat treatment reduced the levels of vascular endothelial growth factor (VEGF), and cyclin D1 compared to the controls (Fig. 3).

In general, many types of anti-cancer agents, including gemcitabine, target DNA and activate apoptotic pathways. However, $\mathrm{NF}-\varkappa \mathrm{B}$ is often activated by anti-cancer agents, such as 5-FU and CPT-11, and NF- $\varkappa \mathrm{B}$ activation is one of the mechanisms through which tumors become resistant to chemotherapy ${ }^{37,38)}$. Therefore, blocking NF- $\varkappa \mathrm{B}$ activation may enhance the anti-tumor effects of chemotherapy and may help prevent chemo-resistance. In this study, gemcitabine activated NF- $\varkappa \mathrm{B}$ binding activity in both AsPC-1 and MIAPaCa-2 pancreatic carcinoma cell lines, and exposure to heat significantly attenuated gemcitabine-mediated $\mathrm{NF}-\varkappa \mathrm{B}$ activation. These observations together with previous reports ${ }^{39,40)}$ strongly suggest that combination therapies consisting of a heat treatment in conjunction with gemcitabine might lead to enhanced cell cytotoxicity in carcinoma cells by blocking the activation of $\mathrm{NF}-\varkappa \mathrm{B}$. Although the inhibition of $\mathrm{NF}-x \mathrm{~B}$ activation by a heat treatment is established ${ }^{41,42)}$, an understanding of the detailed mechanisms through which heat treatments block the activation of $\mathrm{NF}-\varkappa \mathrm{B}$ is lacking. Previous studies from this laboratory have demonstrated that Hsp70 and Hsp32 induced by heat treatment play important roles in the inhibition of $\mathrm{NF}-\varkappa \mathrm{B}$ activation. If heat 

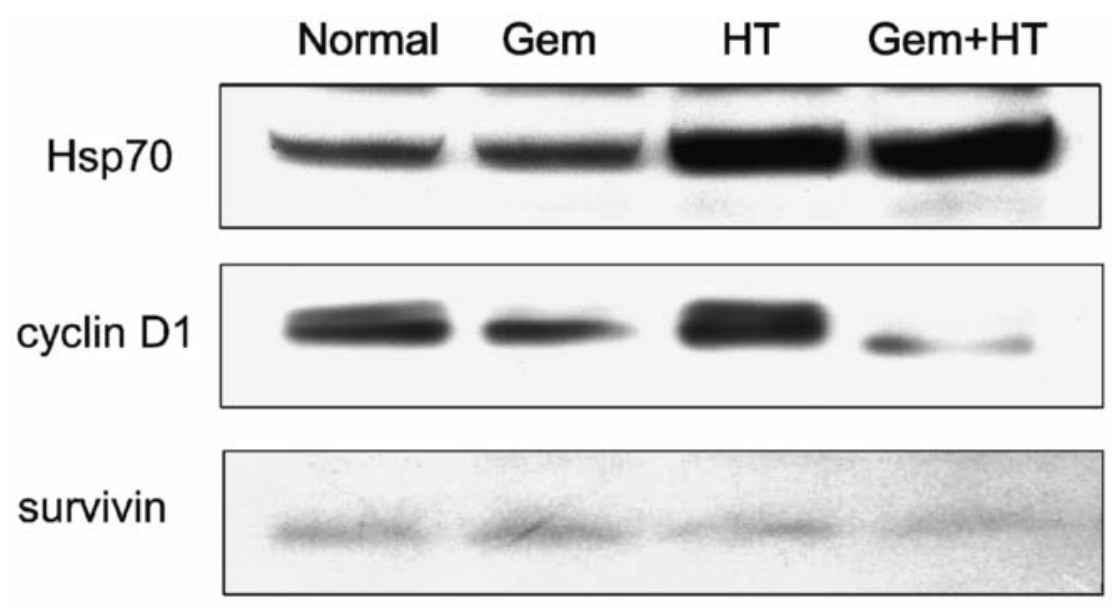

VEGF

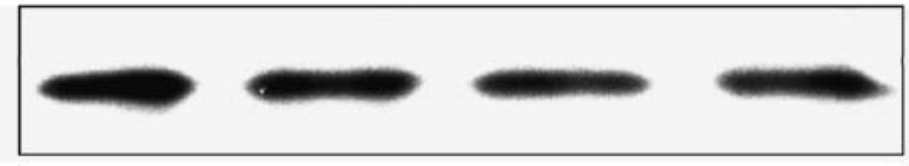

Fig. 3. The expression levels of Hsp70, cyclin D1, surviving, and VEGF. Cells were treated with heat $24 \mathrm{~h}$ before a treatment with gemcitabine (Gem, $30 \mu \mathrm{M}$ ). Whole cell extracts were analyzed with western blotting. The results for no treatment (normal or control), treatment with gemcitabine alone $(30 \mu \mathrm{M})$, heat treatment $(\mathrm{HT})$ alone $\left(43^{\circ} \mathrm{C}, 1 \mathrm{~h}\right)$, and heat treatment combined with gemcitabine treatment are shown. Significant levels of $\mathrm{Hsp} 70$ were induced by heat treatment in MIAPaCa-2 cells. In contrast, gemcitabine treatment alone did not affect the protein levels of Hsp70. The levels of cyclin D1, VEGF were decreased after a heat treatment combined with a gemcitabine treatment.

sensitive proteins such as $\mathrm{Hsp} 70$ and $\mathrm{Hsp} 32$ induced by heat treatment inhibit $\mathrm{NF}-\varkappa \mathrm{B}$ activation and result in the enhancement of gemcitabine-mediated cytotoxicity in AsPC-1 and MIAPaCa-2 cell lines (Fig. 1), the timing of the heat treatment relative to the gemcitabine treatment can be important. Thus, a protocol was used in which the two pancreatic cancer cell lines were treated with gemcitabine and heat with four different intervals between the two agents. AsPC-1 and MIAPaCa-2 cells were treated with heat $24 \mathrm{~h}$ before gemcitabine ( $30 \mu \mathrm{M})$, simultaneously with gemcitabine, $24 \mathrm{~h}$ after gemcitabine, and $48 \mathrm{~h}$ after gemcitabine. The treatment with gemcitabine alone showed significant cytotoxicity. Heat combined with gemcitabine enhanced cytotoxicity, especially when heat was introduced $24 \mathrm{~h}$ before gemcitabine. These observations and previous reports ${ }^{41,42)}$ suggest that heat treatment enhances the cytotoxicity of gemcitabine through the inhibition of NF- $\varkappa$ B. The time course of Hsp70 expression after heat treatment has been examined in AsPC-1 and MIAPaCa-2 cells. Heat induced Hsp70 expression $3 \mathrm{~h}$ after heat was applied, and this induction continued for at least $72 \mathrm{~h}$. Figure 3 shows Hsp70 expression for $72 \mathrm{~h}$ after heat treatment. However, activation of NF- $\varkappa \mathrm{B}$ was initiated between $3 \mathrm{~h}$ and $24 \mathrm{~h}$ after cancer cells were exposed to gemcitabine. It was reported that $\mathrm{NF}-\varkappa \mathrm{B}$ is activated by chemotherapy in some cancer cell lines, and NF- $\varkappa \mathrm{B}$ activation is one of the mechanisms through which tumors become resistant to chemotherapy. Heat treatment-induced heat shock protein $70(\mathrm{Hsp} 70)$ was reported to inhibit I kappa B $(\mathrm{I} \varkappa-B)$ kinase $(\mathrm{IKK})$, resulting in the inhibition of $\mathrm{NF}-\boldsymbol{\varkappa} \mathrm{B}$ activation. Therefore, it 


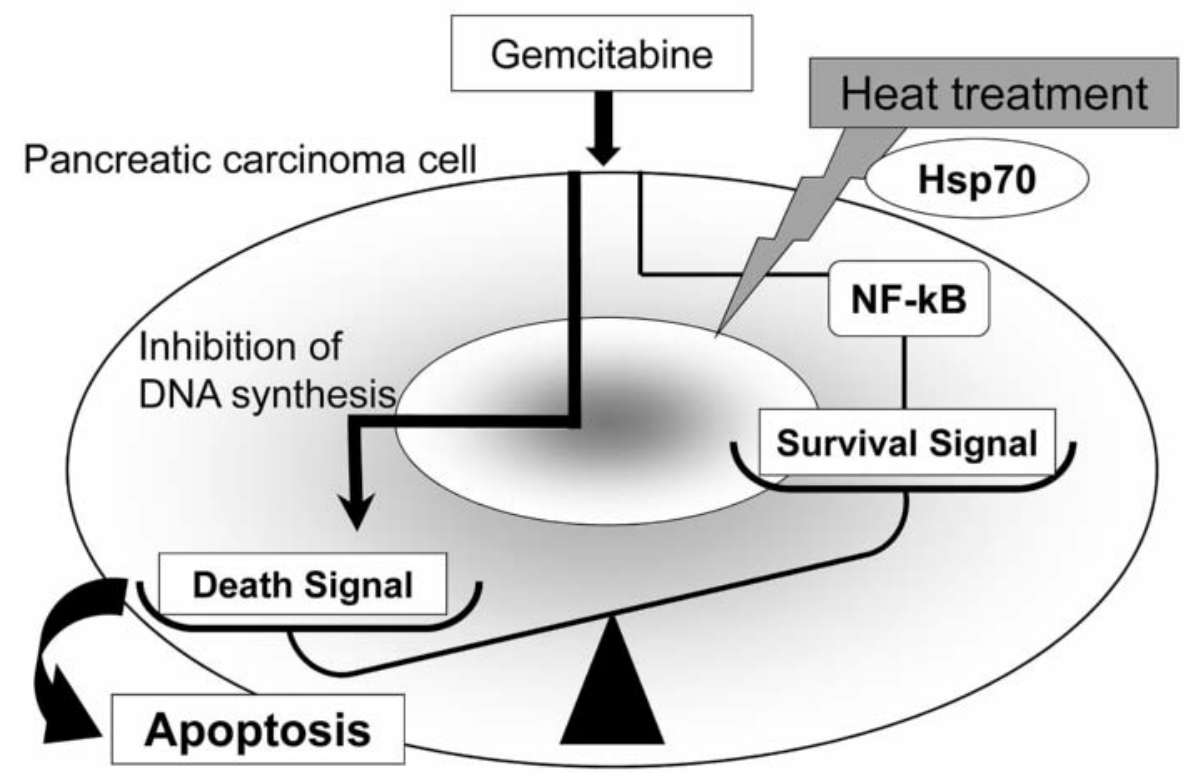

Fig. 4. Gemcitabine actually activates $\mathrm{NF}-\varkappa \mathrm{B}$ in pancreatic carcinoma cells. The activation of $\mathrm{NF}-\varkappa \mathrm{B}$ was inhibited, probably by heat treatment-induced Hsp70. As a result, the death signal was emphasized over the survival signal.

appeared possible that activated $\mathrm{NF}-\varkappa \mathrm{B}$ could be inhibited by a heat treatment in a pancreatic cell line, resulting in the enhancement of gemcitabine-induced cytotoxicity. However, the inhibitory effect of Hsp70 on NF- $\varkappa$ B activation by gemcitabine must occur at an optimal time.

Western blotting analysis (Fig. 3) indicated that the expression of NF- $\varkappa$ B-regulated proteins was inhibited by heat treatment combined with gemcitabine, and suggests that the heat-treatment-mediated inhibition of $\mathrm{NF}-\varkappa \mathrm{B}$ may be effective, not only to inhibit increases in cancer cell numbers in vitro (Fig. 1), but also to inhibit tumor growth in vivo.

Survivin has multiple functions including cytoprotection, inhibition of cell death, and cell-cycle regulation, especially during the mitotic stages, and all of these functions favor cancer cell survival. Many studies on clinical specimens have shown that survivin over-expression is invariably up-regulated in human cancers, is associated with resistance to chemotherapy or radiation therapy, and is linked to a poor prognosis. This suggests that cancer cells survive with the help of survivin ${ }^{43)}$ expression. Survivin promoter activity is basically silent in normal cells, but is strongly expressed in tumor cells ${ }^{44)}$, and this occurs independently of cell types, mitotic status, or genetic makeup. Supporting this model, complementary studies have identified a number of oncogenic gene expression pathways, initiated by activated $\mathrm{NF}-\varkappa \mathrm{B}^{45)}$ and $\mathrm{STAT} 3^{46)}$, which target the survivin promoter to stimulate vigorous transcription selectively in cancer cells. Evidence suggests that these mechanisms include direct, and discrete binding sites for various oncogenic transcriptional activators, and NF- $\varkappa$ B and STAT3 have been identified at the proximal survivin promoter. On the basis of these findings, survivin has been suggested as an attractive target for new anticancer interventions, and survivin inhibitors have recently entered clinical trials ${ }^{44)}$. In this study, there was a decrease in the activation of $\mathrm{NF}-\varkappa \mathrm{B}$ after a treatment with heat plus gemcitabine 
Thermal Med, 26 [3] : 75-85, 2010.

(Fig. 2) ; survivin levels were decreased after a treatment with this combination therapy. This could result in enhancing the induction of apoptosis in AsPC-1 and MIAPaCa-2 cells.

Among proteins related to the G0/G1 phase of cell cycle progression, the expression of cyclin D1 was significantly down-regulated by treatment with gemcitabine alone or a heat treatment in combination with gemcitabine in AsPC-1 and MIA PaCa-2 cells (Fig. 3). A recent study reported that cyclin D1 regulates cell cycle progression and also mitochondrial function and size ${ }^{47)}$. It acts through apoptosis in the carcinoma cell lines, and also through cell cycle delays. According to the data shown in Figure 3, the expression of cyclin D1 was down-regulated by a treatment with gemcitabine alone, and down-regulated to a larger extent by a treatment with heat plus gemcitabine. This suggests that the heat treatment-mediated inhibition of $\mathrm{NF}-\varkappa \mathrm{B}$ lead to the decrease in cell numbers through the induction of apoptosis and the attenuation of cell proliferation.

There is compelling evidence that vascular endothelial growth factor (VEGF) is a major regulator of tumor growth and metastasis ${ }^{48,49)}$. VEGF is secreted at high levels in numerous tumor types, and its expression is associated with a poor prognosis ${ }^{50)}$. From Western Blotting analysis, the decrease of VEGF after exposure to heat plus gemcitabine may help lead to an inhibition of tumor growth in vivo. This scenario is supported by Solorzano et $a l .{ }^{51)}$, which shows that VEGF plays a key role in regulating tumor vascularization, and this is further supported by other studies which indicate that over-expression of $\mathrm{NF}-\varkappa \mathrm{B}$ is a key component of the angiogenic cascade. Such a cascade contributes to VEGF-induced angiogenesis through the up-regulation of VEGF mRNA expression in many tumors ${ }^{52)}$. Although the role of VEGF in tumor angiogenesis is well recognized, it is also a key factor in promoting and sustaining the immune system's lack of response to growing tumors ${ }^{50,53)}$. Tumor-derived VEGF binds to the VEGFR1/FLT1 receptor on CD34+ bone marrow progenitor cells, decreasing the ability of these cells to differentiate into functional dendritic cells ${ }^{54)}$. Therefore it is possible this combination therapy might be improve cancer immunotherapy results in patients.

\section{Conclusion}

In clinical practice, heat treatment is frequently applied simultaneously with an intravenous infusion of anti-cancer agents, or immediately after an intra-arterial infusion of anti-cancer agents. However, in the case of gemcitabine, in order to inhibit the activation of $\mathrm{NF}-\varkappa \mathrm{B}$, it is concluded that heat treatments should be applied before chemotherapy.

\section{References}

1) Dahl O.: Interaction of heat and drugs in vitro and in vivo. "Thermoradiotherapy and Thermochemotherapy Volume 1” Eds. M.H. Seegenschmiedt, P. Fessenden, C.C. Vernon, Springer Verlag, pp.103-121, 1995.

2) Krause S.W., Gastpar R., Andreesen R., Gross C., Ullrich H., Thonigs G., Pfister K., Multhoff G. : Treatment of colon and lung cancer patients with ex vivo heat shock protein 70-peptide-activated, autologous natural killer cells : a clinical phase I trial. Clin Cancer Res, 10 : 3699-3707, 2004.

3) Mukhopadhaya A., Mendecki J., Dong X., Liu L., Kalnicki S., Garg M., Alfieri A., Guha C. : Localized hyperthermia combined with intratumoral dendritic cells induces systemic antitumor immunity. Cancer Res, 67 : 7798-7806, 2007.

4) Milani V., Noessner E., Ghose S., Kuppner M., Ahrens B., Scharner A., Gastpar R., Issels R.D. : Heat shock protein 
70 : role in antigen presentation and immune stimulation. Int J Hyperthermia, 18: 563-575, 2002.

5) Issels R.D. : Hyperthermia adds to chemotherapy. Eur J Cancer, 44 : 2546-54, 2008.

6) Koning G.A., Eggermont A.M., Lindner L.H., Ten Hagen T.L.: Hyperthermia and thermosensitive liposomes for improved delivery of chemotherapeutic drugs to solid tumors. Pharm Res, 27 : 1750-1754, 2010.

7) van der Zee J.: Heating the patient : a promising approach? Ann Oncol, 13 : 1173-1184, 2002.

8) Hahn G.M., Braun J., Har-Kedar I.: Thermochemotherapy: synergism between hyperthermia (42-43 degrees) and adriamycin (of bleomycin) in mammalian cell inactivation. Proc Natl Acad Sci U S A, 72 : 937-940, 1975.

9) Hahn G.M., Shiu E.C. : Effect of pH and elevated temperatures on the cytotoxicity of some chemotherapeutic agents on Chinese hamster cells in vitro. Cancer Res, 43 : 5789-5791, 1983.

10) Warters R.L., Henle K.J. : DNA degradation in Chinese hamster ovary cells after exposure to hyperthermia. Cancer Res, 42 : 4427-4432, 1982.

11) Takahashi A., Matsumoto H., Nagayama K., Kitano M., Hirose S., Tanaka H., Mori E., Yamakawa N., Yasumoto J., Yuki K., Ohnishi K., Ohnishi T. : Evidence for the involvement of double-strand breaks in heat-induced cell killing. Cancer Res, $64:$ 8839-8845, 2004.

12) Rietbroek R.C., Katschinski D.M., Reijers M.H., Robins H.I., Geerdink A., Tutsch K., d'Oleire F., Haveman J. : Lack of thermal enhancement for taxanes in vitro. Int J Hyperthermia, 13: 525-533, 1997.

13) Dumontet C., Bodin F., Michal Y.: Potential interactions between antitubulin agents and temperature : implications for modulation of multidrug resistance. Clin Cancer Res, 4 : 1563-1566, 1998.

14) Mohamed F., Marchettini P., Stuart O.A., Urano M., Sugarbaker P.H.: Thermal enhancement of new chemotherapeutic agents at moderate hyperthermia. Ann Surg Oncol, 10: 463-468, 2003.

15) Mohamed F., Stuart O.A., Glehen O., Urano M., Sugarbaker P.H. : Docetaxel and hyperthermia : factors that modify thermal enhancement. J Surg Oncol, 88 : 14-20, 2004.

16) Knox J.D., Mitchel R.E., Brown D.L. : Effects of hyperthermia on microtubule organization and cytolytic activity of murine cytotoxic T lymphocytes. Exp Cell Res, 194 : 275-283, 1991.

17) Cividalli A., Livdi E., Ceciarelli F., Piscitelli M., Pasqualetti P., Cruciani G., Danesi, D.T.: Hyperthermia and paclitaxel-epirubicin chemotherapy: enhanced cytotoxic effect in a murine mammary adenocarcinoma. Int $\mathrm{J}$ Hyperthermia, 16:61-71, 2000.

18) Othman T., Goto S., Lee J.B., Taimura A., Matsumoto T., Kosaka M. : Hyperthermic enhancement of the apoptotic and antiproliferative activities of paclitaxel. Pharmacology, 62: 208-212, 2001.

19) Michalakis J., Georgatos S.D., Romanos J., Koutala H., Georgoulias V., Tsiftsis D., Theodoropoulos P.A.: Micromolar taxol, with or without hyperthermia, induces mitotic catastrophe and cell necrosis in HeLa cells. Cancer Chemother Pharmacol, 56: 615-622, 2005.

20) Cajone F., Debiasi S., Parker C., Lakshmi M.S., Sherbet G.V.: Metastasis-associated mts1 gene expression is down-regulated by heat shock in variant cell lines of the B16 murine melanoma. Melanoma Res, 4: 143-150, 1994.

21) Barry M.A., Behnke C.A., Eastman A. : Activation of programmed cell death (apoptosis) by cisplatin, other anticancer drugs, toxins and hyperthermia. Biochem Pharmacol, 40 : 2353-2362, 1990.

22) Katschinski D.M., Robins H.I. : Hyperthermic modulation of SN-38-induced topoisomerase I DNA cross-linking and SN-38 cytotoxicity through altered topoisomerase I activity. Int J Cancer, 80 : 104-109, 1999.

23) Le Page S., Kwiatkowski F., Paulin C., Mohamed F., Pezet D., Chipponi J., Benhamed M., Gilly F.N., Glehen O. : In vitro thermochemotherapy of colon cancer cell lines with irinotecan alone and combined with mitomycin C. Hepatogastroenterology, 53 : 693-697, 2006.

24) Makizumi R., Yang W.L., Owen R.P., Sharma R.R., Ravikumar T.S. : Alteration of Drug Sensitivity in Human Colon Cancer Cells after Exposure to Heat: Implications for Liver Metastasis Therapy using RFA and Chemotherapy. Int J Clin Exp Med, 1: 117-129, 2008. 
Thermal Med, $26[3]: 75-85,2010$.

25) Rietbroek R.C., van de Vaart P.J., Haveman J., Blommaert F.A., Geerdink A., Bakker P.J., Veenhof C.H.: Hyperthermia enhances the cytotoxicity and platinum-DNA adduct formation of lobaplatin and oxaliplatin in cultured SW 1573 cells. J Cancer Res Clin Oncol, 123 : 6-12, 1997.

26) Urano M., Ling C.C. : Thermal enhancement of melphalan and oxaliplatin cytotoxicity in vitro. Int J Hyperthermia, $18: 307-315,2002$.

27) Atallah D., Marsaud V., Radanyi C., Kornprobst M., Rouzier R., Elias D., Renoir, J.M. : Thermal enhancement of oxaliplatin-induced inhibition of cell proliferation and cell cycle progression in human carcinoma cell lines. Int $\mathbf{J}$ Hyperthermia, 20 : 405-419, 2004.

28) Makizumi R., Yang W.L., Owen R.P., Sharma R.R., Ravikumar T.S. : Alteration of Drug Sensitivity in Human Colon Cancer Cells after Exposure to Heat: Implications for Liver Metastasis Therapy using RFA and Chemotherapy. Int J Clin Exp Med, 1: 117-129, 2008.

29) Stege G.J., Kampinga H.H., Konings A.W.: Heat-induced intranuclear protein aggregation and thermal radiosensitization. Int J Radiat Biol, 67 : 203-209, 1995.

30) Pereira S., Fernandes P.A., Ramos M.J. : Mechanism for ribonucleotide reductase inactivation by the anticancer drug gemcitabine. J Comput Chem, 25 : 1286-1294, 2004.

31) Rosell R., Danenberg K.D., Alberola V., Bepler G., Sanchez J.J., Camps C., Provencio M., Isla D., Taron M., Diz P., Artal A. : Ribonucleotide reductase messenger RNA expression and survival in gemcitabine/cisplatin-treated advanced nonsmall cell lung cancer patients. Clin Cancer Res, 10 : 1318-1325, 2004.

32) Pace E., Melis M., Siena L., Bucchieri F., Vignola A.M., Profita M., Gjomarkaj M., Bonsignore G.: Effects of gemcitabine on cell proliferation and apoptosis in nonsmall-cell lung cancer (NSCLC) cell lines. Cancer Chemother Pharmacol, 46 : 467-476, 2000.

33) Pourquier P., Gioffre C., Kohlhagen G., Urasaki Y., Goldwasser F., Hertel L.W., Yu S., Pon R.T., Gmeiner W.H., Pommier Y.: Gemcitabine (2',2'-difluoro=2'-deoxycytidine), an antimetabolite that poisons topoisomerase I. Clin Cancer Res, 8 : 2499-2504, 2002.

34) Haveman J., Rietbroek R.C., Geerdink A., Van Rijn J., Bakker P.J. : Effect of hyperthermia on the cytotoxicity of 2',2'-difluorodeoxycytidine (gemcitabine) in cultured SW1573 cells. Int J Cancer, 62: 627-630, 1995.

35) Van Bree C., Beumer C., Rodermond H.M., Haveman J., Bakker P.J.: Effectiveness of 2',2'difluorodeoxycytidine (Gemcitabine) combined with hyperthermia in rat R-1 rhabdomyosarcoma in vitro and in vivo. Int $\mathrm{J}$ Hyperthermia, 15 : 549-556, 1999.

36) Vertrees R.A., Das G.C., Popov V.L., Coscio A.M., Goodwin T.J., Logrono R., Zwischenberger J.B., Boor P.J.: Synergistic interaction of hyperthermia and Gemcitabine in lung cancer. Cancer Biol Ther, 4: 1144-1153, 2005.

37) Wang C.Y., Mayo M.W., Baldwin Jr A.S. : TNF- and cancer therapy-induced apoptosis : Potentiation by inhibition of NFkappaB. Science, 274 : 784-787, 1996.

38) Wang C.Y., Cusack Jr J.C., Liu R., Baldwin Jr A.S. : Control of inducible chemoresistance : Enhanced anti-tumor therapy through increased apoptosis by inhibition of NF-kappaB. Nat Med, 5: 412-417, 1999.

39) Ran R., Lu A., Zhang L., Tang Y., Zhu H., Xu H., Feng Y., Han C., Zhou G., Rigby A.C., Sharp F.R. : Hsp70 promotes TNF-mediated apoptosis by binding IKK gamma and impairing NF-kappaB survival signaling. Genes Dev, 18 : 1466-1481, 2004.

40) Frossard J.L., Pastor C.M., Hadengue A. : Effect of hyperthermia on NF-kappaB binding activity in cerulein-induced acute pancreatitis. Am J Physiol Gastrointest Liver Physiol, 280G : 1157-1162, 2001.

41) Nakabe N., Kokura S., Shimozawa M., Katada K., Sakamoto N., Ishikawa T., Handa O., Takagi T., Naito Y., Yoshida N., Yoshikawa T. : Hyperthermia attenuates TNF-alpha induced up regulation of endothelial cell adhesion molecules in human arterial endothelial cells. Int J Hyperthermia, 23 : 217-224, 2007.

42) Sakamoto N., Kokura S., Okuda T., Hattori T., Katada K., Isozaki Y., Nakabe N., Handa O., Takagi T., Ishikawa T., 
Naito Y., Yoshida N., Yoshikawa T. : Heme oxygenase-1 (hsp32) is involved in the protection of small intestine by whole body mild hyperthermia from ischemia/reperfusion injury in rat. Int J Hyperthermia, 21: 603-614, 2005.

43) Ambrosini G., Adida C. Altieri D.C. : A novel anti-apoptosis gene, survivin, expressed in cancer and lymphoma. Nat Med, 3 : 917-921, 1997.

44) Li F., Altieri D.C.: The cancer antiapoptosis mouse survivin gene: characterization of locus and transcriptional requirements of basal and cell cycle-dependent expression. Cancer Res, 59: 3143-3151, 1999.

45) Kawakami H., Tomita M., Matsuda T., Ohta T., Tanaka Y., Fujii M., Hatano M., Tokuhisa T., Mori N.: Transcriptional activation of survivin through the NF-kappaB pathway by human T-cell leukemia virus type I tax. Int J Cancer, 115 : 967-974, 2005.

46) Siddiquee K., Zhang S., Guida W.C., Blaskovich M.A., Greedy B., Lawrence H.R., Yip M.L., Jove R., McLaughlin M.M., Lawrence N.J., Sebti S.M., Turkson J.: Selective chemical probe inhibitor of Stat3, identified through structure-based virtual screening, induces antitumor activity. Proc Natl Acad Sci U S A, 104 : 7391-7396, 2007.

47) Sakamaki T., Casimiro M.C., Ju X., Quong A.A., Katiyar S., Liu M., Jiao X., Li A., Zhang X., Lu Y., Wang C., Byers S., Nicholson R., Link T., Shemluck M., Yang J., Fricke S.T., Novikoff P.M., Papanikolaou A., Arnold A., Albanese C., Pestell R. : Cyclin D1 determines mitochondrial function in vivo. Mol Cell Biol, 26: 5449-5469, 2006.

48) Ferrara N., Alitalo K. : Clinical applications of angiogenic growth factors and their inhibitors. Nat Med, 5 : 1359-1364, 1999.

49) Folkman J.: Angiogenesis in cancer, vascular, rheumatoid and other disease. Nat Med, 1: 27-31, 1995.

50) Ohm J.E., Carbone D.P. : VEGF as a mediator of tumor-associated immunodeficiency. Immunol Res, 23: 263-272, 2001.

51) Solorzano C.C., Jung Y.D., Bucana C.D., McConkey D.J., Gallick G.E., McMahon G., Ellis L.M. : In vivo intracellular signaling as a marker of antiangiogenic activity. Cancer Res, 61: 7048-7051, 2001.

52) Fujioka S., Sclabas G.M., Schmidt C., Frederick W.A., Dong Q.G., Abbruzzese J.L., Evans D.B., Baker C., Chiao P.J. : Function of nuclear factor kappaB in pancreatic cancer metastasis. Clin Cancer Res, 9: 346-354, 2003.

53) Gabrilovich D., Ishida T., Oyama T., Ran S., Kravtsov V., Nadaf S., Carbone D.P. : Vascular endothelial growth factor inhibits the development of dendritic cells and dramatically affects the differentiation of multiple hematopoietic lineages in vivo. Blood, 92 : 4150-4166, 1998.

54) Dikov M.M., Ohm J.E., Ray N., Tchekneva E.E., Burlison J., Moghanaki D., Nadaf S., Carbone D.P.: Differential roles of vascular endothelial growth factor receptors 1 and 2 in dendritic cell differentiation. J Immunol, 174 : 215-222, 2005. 